\title{
onmbalina
}

(8)

\section{La pervivencia de los clásicos en una obra histórica de Lope de Vega}

Autor(es): $\quad$ Antunes, Andréa

Publicado por: Centro de Estudos Clássicos e Humanísticos da Universidade de

URL

persistente: URI:http://hdl.handle.net/10316.2/30166

DOI: $\quad$ DOI:http://dx.doi.org/10.14195/978-989-721-038-9_3

Accessed : $\quad$ 26-Apr-2023 10:17:15

A navegação consulta e descarregamento dos títulos inseridos nas Bibliotecas Digitais UC Digitalis, UC Pombalina e UC Impactum, pressupõem a aceitação plena e sem reservas dos Termos e Condições de Uso destas Bibliotecas Digitais, disponíveis em https://digitalis.uc.pt/pt-pt/termos.

Conforme exposto nos referidos Termos e Condições de Uso, o descarregamento de títulos de acesso restrito requer uma licença válida de autorização devendo o utilizador aceder ao(s) documento(s) a partir de um endereço de IP da instituição detentora da supramencionada licença.

Ao utilizador é apenas permitido o descarregamento para uso pessoal, pelo que o emprego do(s) título(s) descarregado(s) para outro fim, designadamente comercial, carece de autorização do respetivo autor ou editor da obra.

Na medida em que todas as obras da UC Digitalis se encontram protegidas pelo Código do Direito de Autor e Direitos Conexos e demais legislação aplicável, toda a cópia, parcial ou total, deste documento, nos casos em que é legalmente admitida, deverá conter ou fazer-se acompanhar por este aviso.

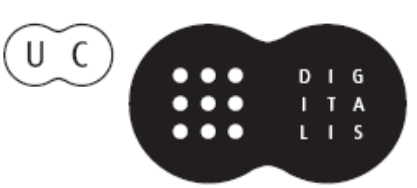




\section{De ayer a hoy}

\section{Influencias clásicas en la literatura}

\section{Aurora López, Andrés Pociña, Maria de Fátima Silva (coords.)}




\title{
LA PERVIVENCIA DE LOS CLÁSICOS EN UNA OBRA HISTÓRICA DE LOPE DE VEGA
}

\author{
Andréa Antunes
}

Escola Politécnica de Saúde Joaquim Venâncio

\begin{abstract}
La presente investigación tiene como objetivo comprobar la supervivencia de los clásicos en la obra histórica del dramaturgo español Lope de Vega El Principe Perfecto. El rey portugués D. João II es el protagonista de su propio vivir en la obra de este gran dramaturgo. A través de la utilización de los modelos clásicos, y de los aspectos que hacen de este rey un paradigma monárquico son evidenciados porque lo compara a los grandes héroes de la historia universal.
\end{abstract}

Félix Lope de Vega Carpio es considerado el creador del drama español. $\mathrm{Su}$ producción literaria es excepcional. No solo por la cantidad de obras, sino también por su calidad. Su obra maestra es El arte nuevo de hacer Comedias, donde define y enseña a escribir comedias. Además de la presencia del trágico y del cómico, están presentes en su teatro elementos que resaltan la memoria colectiva del pueblo español. Sus fuentes de inspiración son las leyendas tradicionales y la historia, por lo que sus temas favoritos son los que exaltan este sentimiento nacional (que rescata del pasado las glorias españolas); los de honor (un sentimiento propio de la sociedad española de la época); y el ideal religioso (lo que exalta al maravilloso y al miraculoso).

Los asuntos mitológicos forman parte de un campo de relieve entre los dramaturgos del "Siglo de Oro". Y no podría ser diferente en Lope. Entre sus obras más significativas sobre este tema, podemos subrayar Adonis y Venus - que se basa en el mito de Adonis, al que se agrega el de Atalanta - El Vellocino de Oro - sobre el mito griego que aparece en la historia de Jasón y los Argonautas- y El laberinto de Creta -una lectura del mítico héroe griego Teseo y el Minotauro.

La obra El Principe Perfecto está inserida entre las Comedias Históricas del dramaturgo Lope de Vega, fue puesta en escena, así como la mayor parte de su producción, durante el reinado de Felipe III, cuando Portugal está bajo la corona de España. Este rey pasó a la historia como un "rey débil"1, sin grandes hechos, que abandonó el poder en manos del duque de Lerma, provocando en la gente un sentimiento de desamparo. Fue en esta época que el teatro llegó a su máximo esplendor y la escena dramática fue ofrecida a un público que abarcaba todas las escalas sociales. Momento

\footnotetext{
${ }^{1}$ Díaz-Plaja, Fernando, La Vida y la Época de Felipe III, España, Editorial Planeta, 1997
} 
oportuno poner en relieve un monarca virtuoso y templado, un espejo de reyes.

Como ya mencionado, la obra El Principe Perfecto cuéntanos la historia del rey D. Juan II, nacido en el año de 1455, en Lisboa, hijo de los reyes D. Alfonso y D. Isabel, de Portugal. A través de la réplica de los personajes y por el ingenio del dramaturgo, el carácter de este rey es primorosamente construido. Y muchas son las situaciones teatrales en las que podemos comprobar la pervivencia de los clásicos en esta obra lopesca, principalmente cuanto a la conciliación entre el cristianismo y el paganismo.

Así que, en el primero acto de la obra, el entonces príncipe D. Juan en una lucha mata a un hombre. Pero, esto no causa ninguna mácula a la figura de tan justo y virtuoso príncipe. Por la conducción del dramaturgo este asesinato se convierte en una actitud de heroísmo e ingenio. Comprobamos en la situación teatral $n^{\circ}$, en un diálogo entre los personajes Clara y Esperanza:

(...) ESPERANZA - ¡Qué notable gallardía!

¡Matar uno y herir tres!

CLARA - El es hombre que en Castilla

le tienen por maravilla

del mundo: un Hércules es.

En la batalla de Toro

fue divino su valor...

En fin salió vencedor.

En África tiembla el moro

desde que le vio en Arcila

acometer la muralla. (...)"2

Cuando recurre al mito griego del héroe Hércules, hijo de Zeus y de la mortal Alcmena, símbolo de fuerza y coraje, el dramaturgo ya empieza a desvelar que D. Juan no es un hombre cualquiera, es un ejemplo adonde puso Dios grandezas tales que está más allá de lo que es humano, llega a lo que es celestial.

La "situación" teatral 1 es la más significativa en la obra de Lope, es el "retrato" del rey D. Juan II, ofrecido a los reyes católicos D. Fernando y D. Isabel, a través de la réplica del personaje D. Juan de Sosa, que allí está de embajador. La reina D. Isabel se vuelve curiosa respecto al rey D. Juan II:

REINA. - El hombre que he deseado ver con mayor aficción

${ }^{2}$ Vega, Lope de, El Príncipe Perfecto, en Obras Escogidas, Teatro, II, Ed. de Federico Carlos Sainz de Robles, Madrid, Aguilar, 1987, p. 1113. 
es vuestro Rey.

D.JUAN. - Si pintado

de mi corta relación

con más verdad que cuidado,

señora, le queréis ver,

podré, haciéndole, correr

la cortina a su retrato ${ }^{3}$.

En este momento, el personaje D. Juan de Sosa empieza la construcción primorosa de la imagen del magnánimo y valeroso rey, donde se mezclan rasgos físicos y morales:

El invicto Rey don Juan

el Segundo, aunque el primero

en el heroico valor,

en el militar esfuerzo,

Rey tercio de Portugal,

desde el Santo Alfonso el Bueno

a quien dio sus mismas llagas

por armas el Rey del cielo,

es hombre proporcionado

de suerte en mediano cuerpo,

con tal rostro e gravedad

que entre mil hombres diversos

le conocerán por Rey;

que luego obliga a respeto"4.

D. Juan de Sosa sigue con sus consideraciones respeto al rey, ahora comparándole al gran paradigma monárquico: el rey Salomón. Leemos:

Desde que volvió su padre, a quien volvió a dar el reino que le había dado en vida, digna hazaña de su pecho, ningún sábado ha dejado de ver los presos y pleitos, que allá relación llamamos, en que parece que vemos un ejemplo de Salomón con divino entendimiento 5 .

\footnotetext{
${ }^{3}$ Ibid, p. 1117.

${ }^{4}$ Ibid, p. 1117.

${ }^{5}$ Ibid, p. 1117.
} 
Salomón fue un rey respetado por todas las religiones. Según los escritos no era una persona común, tampoco un santo, solo tenía una gran sabiduría y estaba muy por delante de los hombres de su tiempo.

Se le conoce como el "rey constructor" porque recibió de su padre, David, la tarea de construir el Templo de Jerusalén, dedicado al Dios de Abraham, donde debería guardarse el Arca de la Alianza con las Tablas de la Ley. Después de la construcción del templo, Salomón lo convirtió en un lugar para el perfeccionamiento de los seres humanos.

Siguiendo con el "retrato", un otro mito clásico es usado como referencia para exaltar a los atributos de este rey:

Es en el dar Alejandro, pero da mejor que el griego;

que él miró la propia fama

y este el ajeno provecho ${ }^{6}$.

La utilización del modelo de Alejandro Magno no es solo debido a la muestra de la generosidad de este emperador, sino también a los proyectos emprendidos por él, que dominaba un área de alrededor de 3,8 millones de kilómetros cuadrados siendo uno de los grandes conquistadores de la humanidad. Fundó más de 80 ciudades, entre ellas Alejandría, considerada la “joya de la corona”. Y además de ser un señor de la guerra, tenía una pasión por la música, la poesía y fue un discípulo de Aristóteles. Ha creado colonias militares para difundir la civilización a los bárbaros, y también se rodeó de eruditos y artistas que difundieron la cultura helénica.

Lo mismo se aplica a D. Juan II, era reverenciado por su ideal expansionista. En su gobierno las exploraciones portuguesas en la costa africana eran prioridades, buscando llegar hasta la India. Además de muchos otros logros, como por ejemplo el inicio de la colonización de las islas Santo Tomé y Príncipe. Y era igualmente admirado por sus modales elegantes y refinados.

Sigue D. Juan de Sosa con la caracterización del rey. Habla de las cosas de placer de D. Juan II haciendo una comparación al gran rey persa Ciro:

\footnotetext{
Son sus entretenimientos músicas, toros y danzas, ver luchar fuertes mancebos y ejercitar varias armas... Pero vanamente emprendo no siendo yo Jenofonte,
}

${ }^{6}$ Ibid, p. 1117. 
pintaros con rudo ingenio

$\tan$ nuevo cristiano Ciro; ${ }^{7}$

Cuéntanos la historia que Ciro, este gran conquistador, también legisló, así como D. Juan II, según preceptos divinos. Es lo que comprobamos con el siguiente pasaje bíblico:

"Ciro, rei da Pérsia, decreta: Javé, o Deus do céu, entregou a mim todos os reinos do mundo. Ele me encarregou de construir para ele um Templo em Jerusalém, na terra de Judá. Todos os que pertencem a esse povo e vivem entre nós, podem voltar para lá. E que Javé, seu Deus, esteja com eles"8.

Y con los últimos versos a los reyes católicos la imagen del rey es edificada y empleada como ejemplaridad por el dramaturgo:

porque tengo por muy cierto

que para ejemplo de reyes

hizo este Príncipe el cielo?

La capacidad y el ingenio de este dramaturgo a través de las réplicas de sus personajes, desvela a nosotros su erudición y competencia para utilizar referencias clásicas en sus obras. Esto señala la pervivencia de estos modelos en el teatro español del siglo XVII. Es decir, Lope de Vega supo enlazar los temas barrocos con los clásicos, lo que confirió a sus comedias un carácter propio, un carácter transformador.

\footnotetext{
${ }^{7}$ Ibid, p. 1117.

${ }^{8}$ (Crónicas 36:23) In A Bíblia Sagrada., Op. Cit. P.498

${ }^{9}$ Ibid, p. 1117.
} 


\section{Bibliografía}

Delerue, Maria Luisa - Oliveira, Maria Manuela, D. João II: Um Rei Emblemático, Lisboa, Grupo de Trabalho do Ministério da Educação para as Comemorações dos Descobrimentos Portugueses, 2000.

Díaz-Plaja, Fernando, La Vida y la Época de Felipe III, España, Editorial Planeta, 1997.

García, José Manuel, Breve Panorama Bio-bibliográficosobre D. João II, Comissão Nacional para as Comemorações dos Descobrimentos Portugueses, Lisboa, 1999.

Guinsburg,J. - Coelho Netto, José Teixeira - Cardoso, Reni Chaves, Semiologia do Teatro, São Paulo, Perspectiva, 1988.

Le Goff, Jacques, Uma Vida para a História: conversações com Marc Hergoun, Editora UNESP, 1994.

—_, O Imaginário Medieval, Editorial Estampa, 1994.

___ Para um Novo Conceito de Idade Média, Editorial Estampa, 1979.

—_- São Luis, tradução de Marcos de Castro, Rio de Janeiro, Record, 1999.

Moises, Massaud, A Literatura Portuguesa Através dos Textos, São Paulo, 14a edição, Editora Cutrix, 1985.

Pina, Rui de, Crónicas, Porto, Lello \& Irmãos - Editores, 1977.

Resende, Garcia de, Crônica de D. João II e Miscelânea, Lisboa, Imprensa Nacional - Casa da Moeda, 1973.

Rodrigues, Maria Idalina Resina, De Gil Vicente a Lope de Vega: Vozes Cruzadas no Teatro Ibérico, Lisboa, Editorial Teorema Ltda, 1999.

Serrão, Joaquim Veríssimo, História de Portugal, Volume I: Estado, Pátria e Nação (1080-1415), 2. a ed., Lisboa, Verbo, 1978.

Vega, Lope de, El Principe Perfecto, en Obras Escogidas, Teatro, II, Ed. de Federico Carlos Sainz de Robles, Madrid, Aguilar, 1987.

__ _ El Príncipe Perfecto, en Obras Escogidas, Tomo II - Poesía, Lírica, Poema, Prosa, Novelas, Ed. de Federico Carlos Sainz de Robles, Madrid, Aguilar, 1953.

- El Mejor Mozo de España in Obras Escogidas, Teatro, Tomo III. Madrid, Ed. Aguilar, 1987. 
Peres, Lygia Vianna, A Tecedora de Espanha ou O Sonho da Infanta: Leitura de El Mejor Mozo de España de Lope de Vega, in Arrabaldes, Cadernos de História, série I, Cultura e Imaginário no Ocidente Medieval, Org. Fróes, Vânia Leite. Niteroi, ICHF/UFF, 1996.

—_- La Historia en el Teatro, el Teatro de la Historia. La tradición emblemática y la representación de algunos reyes peninsulares en obras del "Siglo de Oro", In "Actas del V Congreso de la Asociación Internacional Siglo de Oro", Münster, Iberoamericana Vervuert, 1999.

http://www.ricardocosta.com/

http:// www.artehistoria.com/historia/personajes 